\title{
(2) OPEN ACCESS \\ Integrating and maintaining automated external defibrillators and emergency planning in community sport settings: a qualitative case study
}

\author{
Lauren V Fortington (1) , ${ }^{1}$ Sheree Bekker (1) , ${ }^{2}$ Caroline F Finch (1) ${ }^{1}$
}

\begin{abstract}
Handling editor Kirsty Challen
Additional material is published online only. To view please visit the journal online (http://dx.doi.org/10.1136/ emermed-2019-208781).

${ }^{1}$ Exercise Medicine Research Institute, School of Medical and Health Sciences, Edith Cowan University, Joondalup, Western Australia, Australia

${ }^{2}$ Department for Health, University of Bath, Bath, UK
\end{abstract}

Correspondence to Lauren V Fortington, Exercise Medicine Research Institute School of Medical and Health Sciences, Edith Cowan University, Joondalup, WA 6027, Australia;

l.fortington@ecu.edu.au

Received 26 May 2019 Revised 27 January 2020 Accepted 2 May 2020 Published Online First 16 June 2020

Check for updates

(c) Author(s) (or their employer(s)) 2020. Re-use permitted under CC BY-NC. No commercial re-use. See rights and permissions. Published by BMJ.

To cite: Fortington $\mathrm{LV}$,

Bekker $S$, Finch CF.

Emerg Med J

2020:37:617-622

\section{ABSTRACT}

Introduction A voluntary State Government-led programme in Victoria, Australia 'Defibrillators for Sporting Clubs and Facilities Program' ran from 2015 to 2019, broadly aimed at increasing access to automated external defibrillators (AEDs), together with a greater number of community members trained for management of medical emergencies. This study aimed to understand whether participating sport clubs/facilities had successfully integrated an AED and medical planning with other club/facility safety practices, 12 months after delivery of the programme.

Methods This was a qualitative case study of 14 sport clubs/facilities in Victoria, Australia in 2017, underpinned by the Reach, Effectiveness, Adoption, Implementation, Maintenance (RE-AIM) framework. We conducted observational audits of facilities (to locate AED placement, signage and other relevant location-specific factors) and semi-structured, face-to-face interviews with representatives of the clubs/facilities. Interview questions were designed to determine if and how the related, mandated emergency management programme was adapted for the long term (embedding), whether this aligned to ongoing organisational mission (active engagement), and whether or not it was still ongoing 6 months postinitial implementation (sustainability). Data were evaluated using qualitative descriptive methodology. For reporting, descriptive summaries of the audit were combined with interview data to contextualise and visualise the sport club/facility setting and key results.

Results Key issues identified were accessibility and visibility of the AED, with inadequate signage and challenges identifying an efficient location for access and storage. Most interviewees reported the AED and training were received with no further actions taken towards safety planning or integration with club/facility practice. Several challenges regarding remaining up to date with training and ensuring required routine checks of the AED take place were also raised.

Conclusions This study identified several challenges for community sport clubs/facilities in the implementation of an AED and medical planning programme, including where to store the AED, how to make its presence known to the community and how to integrate changes alongside other club/facility practices.

\section{BACKGROUND}

Sudden cardiac arrest (SCA) is the leading cause of fatalities in sport-settings worldwide. ${ }^{1}$ Improved outcomes occur when there is a rapid emergency

\section{Key messages}

What is already known on this subject

- How sport communities can best access, manage and integrate injury prevention practices into broader risk management processes is an important knowledge gap. One area of particular concern is the need for community sport to be adequately prepared for the risk of adverse cardiac events.

\section{What this study adds}

- This qualitative case study shows that, despite government provision of an AED, typical community sport clubs/facilities are potentially under-prepared for a cardiac emergency. Several practical strategies are recommended such as improving AED visibility in the clubhouse and the provision of larger signs designed for outdoor use.

response, consisting of recognition, cardiopulmonary resuscitation and, where indicated, use of an automated external defibrillator (AED). ${ }^{2}$ The AED is a transportable device that can be used by laypersons without medical training. Thus, for bystanders, knowing what an AED is, and that there is one available nearby, is an important component of emergency response planning. There is growing international focus in sport settings towards AED promotion and uptake. ${ }^{3}$ Several sports and health agencies recommend, or mandate, the availability of an AED at all competitions and training, including the Australian College of Sport and Exercise Physicians. ${ }^{4}$ These recommendations for AED availability are in place despite little understanding of, or support for, the practicalities involved in actually bringing a new safety programme, such as AED provision, into a sports club/facility successfully.

There are well-known challenges in implementing and maintaining safety programmes and risk management strategies into sport settings. ${ }^{5}$ Adaptations commonly need to be made to programmes from how they are originally designed to be used $^{67}$ owing to the diversity of physical settings and organisational structures within community sport environments. A prior survey of knowledge and confidence of AED use in sport settings identified several difficulties in embedding an AED and safety documentation into club/facility processes. ${ }^{8}$ Difficulties with programme implementation have 
also been documented in evaluations of AED use in general community spaces, particularly around the awareness and accessibility of the device. ${ }^{910}$ From these studies, it has been suggested that training, education and better signage would encourage more people to feel comfortable with using AEDs in an emergency situation. $^{1112}$

There is likely to be increased expectation for AED availability in sport settings as a practical solution for community sport to manage SCA. Identifying what works for whom and what does not, will help with the design of future AED programmes delivered through sport. This study aimed to describe the experiences of community sport clubs/facilities with implementing a voluntary, government-led AED provision and training programme. Programme participants were followed up at 6-12 months postdelivery of an AED and training at their club/facility to consider the extent to which medical emergency planning, inclusive of the $\mathrm{AED}$, had been integrated into routine safety and risk management practices.

\section{METHODS}

\section{Ethics}

Potential participants were contacted initially by LVF by telephone. The project was described and their interest in study participation determined. Participants were subsequently sent a plain language information statement about the study by email. Following agreement, a convenient time and location for data collection was confirmed. Informed consent was explained and signed at the time of the interview/site visit.

\section{Setting and description of programme}

In 2015, the Victorian Government Department of Health and Human Services, launched a 'Defibrillators for Sporting Clubs and Facilities Program' (DSCF program) (pdf of programme available from first author as details are no longer online). The voluntary programme aimed to increase the number and confidence of community members in the management of medical emergencies, including the use of AEDs. In return for the provision of an AED free of charge, the programme required eight to 10 club members to attend tailored training on AED operation and basic life support. An additional aim of the programme was to embed awareness of safety practices and planning for medical emergencies within the participating sporting clubs/ facilities. In signing up to the programme, clubs/facilities agreed to update, or develop, a written medical emergency plan. An example plan, from Sports Medicine Australia (SMA) (www. https://sma.org.au/resources-advice/policies-and-guidelines/ medical-emergency-plannning-guide/), was made available to participants to facilitate this task. In an earlier qualitative study, we presented information on the motivations to take part in the DSCF programme, finding a large proportion of clubs/facilities signed up to the programme because the AED was provided free of charge. ${ }^{3}$ Subsequently, drawing on findings from a crosssectional survey of programme knowledge and confidence by club/facility members, we suggested improvements to the DSCFprogramme integration could be made through stronger consideration of how the AED fits with other club/facility practices. ${ }^{8}$

\section{Study design}

This study used a qualitative case study design. ${ }^{13}$ Case studies allow for in-depth research into a predetermined setting, location or context, such as a specific intervention, group or individual, bound by time and activity. ${ }^{12}$ We focused on the setting of community sport clubs/facilities and the activity/timing of those who had been provided with an AED and training 6-12 months earlier. For this study, we conducted face-to-face interviews, supplemented with direct observation of the AED location and visibility within the club/facility.

The case study was designed around the maintenance domain for settings of the 'Reach Effectiveness Adoption Implementation Maintenance' framework (RE-AIM). ${ }^{14}{ }^{15}$ The RE-AIM framework was chosen as it is well regarded for assessing the implementation of public health interventions and for evaluating their uptake. It is known that implementation of injury prevention interventions in sport settings is relatively successful in the short term, but the longer term outcomes are often not followed up. ${ }^{16}$ Within RE-AIM, the maintenance domain considers the extent to which an intervention is sustained in the longer term.

The RE-AIM Model Dimension Items Checklist presents four criteria to consider when using the framework, specific to maintenance at the setting level, ${ }^{17}$ three of these form our analysis themes of embedding, sustainability and active engagement. The fourth relates to our use of qualitative methods. The criteria, together with our application for each, are presented in table 1 .

\section{Participants}

As an original condition of participation in the DSCF programme, contact details of individuals and clubs/facilities were provided to the agency delivering the programme, together with consent for the agency to share these details for research purposes. A selection of representative clubs/facilities was made from 186 of the first 200 clubs/facilities in the broader programme (14 clubs/facilities that had participated in our earlier qualitative study were excluded to avoid additional burden). ${ }^{3}$ The sampling method ensured that a range of clubs/facilities was included

Table 1 Assessing AED programme maintenance at the community sport setting level

\begin{tabular}{|c|c|c|}
\hline \multicolumn{2}{|c|}{ Maintenance criteria (setting level) from the Model Dimension Items Checklist ${ }^{17}$} & \multirow{2}{*}{$\begin{array}{l}\text { Application in this study } \\
\text { We conducted a qualitative case study using face-to-face interviews and } \\
\text { observational data collection }\end{array}$} \\
\hline Qualitative methods & $\begin{array}{l}\text { The use of qualitative methods to understand setting level } \\
\text { institutionalisation }\end{array}$ & \\
\hline Embedding & If, and how, the programme was adapted for the long term & $\begin{array}{l}\text { The following questions were explored: } \\
\text { Was the programme suited to the club/facility needs? Were changes made from } \\
\text { the way the DSCF programme had been intended for delivery? What changes } \\
\text { were made? }\end{array}$ \\
\hline Sustainability & $\begin{array}{l}\text { If the programme is still ongoing after } 6 \text { months post } \\
\text { programme delivery }\end{array}$ & $\begin{array}{l}\text { The following question was explored: } \\
\text { Was there evidence of the DSCF programme in place at the club/facility at the } \\
\text { time of interview? }\end{array}$ \\
\hline Active engagement & $\begin{array}{l}\text { A measure or discussion of alignment to organisation mission } \\
\text { or sustainability of business model }\end{array}$ & $\begin{array}{l}\text { The following question was explored: } \\
\text { Has the sport club/facility adjusted or realigned parts of their processes to } \\
\text { incorporate the intentions of the DSCF programme? }\end{array}$ \\
\hline
\end{tabular}

Application in this study observational data collection were made?

Was there evidence of the DSCF programme in place at the club/facility at the time of interview?

incorporate the intentions of the DSCF programme?

AED, automated external defibrillator; DSCF, Defibrillators for Sporting Clubs and Facilities. 
with different participant numbers and age groups as well as a mix of indoor/outdoor, land-based/water-based and individual/ team sports, including soccer, athletics, tennis, golf, sailing, lawn bowls, Australian football, netball, lifesaving, rowing, hockey and mixed sport centres. Clubs/facilities were chosen initially for convenience of access by the research team's regional location (Central Victoria, Australia) and subsequently, metropolitanbased (Melbourne) clubs/facilities were chosen based on different available sports. The selection and number of clubs included mirrored the methods and justification from our first study. ${ }^{3}$ One representative from each club participated as interviewee. The interviewee was either the person who initiated the application or a senior representative of the club (President or Chief Executive) who had oversight of the club practices and the application to the DSCF programme. The number of interviews aligned with what is generally considered acceptable for achieving meaning saturation within qualitative interviews. ${ }^{18}$

\section{Procedures}

Face-to-face interviews with representatives from 14 clubs/ facilities were conducted by SB in August 2017. Participants provided signed consent forms before the interview. Interviews were between 10 and $20 \mathrm{~min}$ in duration and conducted using a semistructured, open-ended question and prompt format (online supplementary file 1). Interviews were digitally recorded for transcription and analysis purposes. Audio data were professionally transcribed and uploaded into NVivo V. 11 qualitative data analysis software for analysis.

Observational data collection was also undertaken during the interview visits at 13 of the 14 clubs/facilities (one facility was being renovated and so not accessible). Author LVF completed a short checklist of items and mapped out the club/facility, noting the AED position, emergency instructions and signs and other features relevant for analysis. The items were derived from best practice (described in the SMA plan provided) and from similar previous research ${ }^{10}{ }^{19}$ (available in online supplementary file 2) as there were no requirements formally specified in the programme documentation on how or where to store the AED. Photographs were taken to validate data and for presentation purposes in the analysis. Additional field notes were taken to assist with interpretation and recall in data analysis.

\section{Analysis}

A qualitative descriptive analysis was used as an approach suitable for exploring questions of relevance to policymakers and practitioners. ${ }^{20}$ This method transforms interview data into 'the presentation of the facts of the case in everyday language', without the need for highly abstract rendering or theorising. ${ }^{20}$ Analysis focused on identifying common considerations and processes around AEDs and their implementation that these participants had engaged in, and commonalities identified between settings. Open-coded themes were developed across three maintenance criteria: embedding, sustainability and active engagement. Finally, descriptive summaries (written and photographic) of the observational audit were combined with interview transcripts to contextualise and visualise the setting and key findings. This interview data analysis was primarily undertaken by SB with review and input from the other authors who assisted with the terminology around developing themes. The combined audit summaries were primarily developed by LVF, with review and input from SB and CFF.

Results are reported descriptively, as a time line of events, from receipt of the AED and training through to the long-term sustainability of medical planning. The physical placement, accessibility and the visibility of the AED is reported first to 'set the scene' as this information contextualises the subsequent results. Typically, AED placement was identified primarily from the observational data, with information from the interviews providing details on the location choice.

\section{RESULTS}

\section{Location, accessibility and visibility of the AED}

Observational data collected at 13 of the clubs/facilities (one facility was under renovation at the time and inaccessible) identified that all AEDs were located inside a building, such as a clubhouse or similar secure location. The location used was not always characterised by high visibility but rather, was chosen because it was considered accessible to the playing or social areas.

I guess, because it's not a huge clubhouse, we thought that no matter where we put it people would soon become aware of its location. That just seemed a convenient little unused corner that was accessible. (INTERVIEW C)

Decisions on where to place the AED were made by the representative of the first-aid provider in consultation with club/ facility members or management.

So the positioning of it and the signage that was all suggested by the ambo [ambulance] guy, and he's the expert. We said, yes, we'll put it there. (INTERVIEW A)

There was a bit of discussion, quite a few people thought it should have been here....[facilitator: next to the door?] Yeah. But I think I made a decision....I just thought it was a bit less conspicuous. It's still quite obvious there; it's just a bit out of the way I thought. It's quite a valuable item; I think it would be more secure in that corner. (INTERVIEW M)

Security of the AED was an identified concern. For all clubs, public access to the AED was restricted to the opening hours of all clubs/facilities. The decision to fully secure the AED behind locked doors after hours was due largely to concerns of vandalism and misuse.

Okay, so that was probably my decision. It's really where it's visible but it's not going to be, if you like, tampered with by general public. It needs to be in a spot where I know I can see it and people can see it. It's tucked away because occasionally there are functions here and we have known things to move [laughs] but it's so visible that's it [is] there and it's easy. So if you get the defib, it's by the bar, so they know exactly where it is. That was the decision. We didn't want to have it outside for those reasons, so it's in here at all times. (INTERVIEW E)

From the observational data, we identified signage situated external to the club/facility building at 10 locations in the form of sticky-back plastic signs measuring $10 \mathrm{~cm}$ x $15 \mathrm{~cm}$. These were noted as being small and difficult to see from a distance (figure 1). The stickers provided with the AED proved unsuitable for outdoor use, being worn or faded within 6-12 months.

All clubs/facilities also had some form of signage in the AED location's immediate area. Stickers were the most commonly used signage and for some, larger printed signs were in place. Five locations had signage located internally but away from the AED location.

\section{Embedding}

Medical emergency planning, and associated documentation, varied significantly among clubs/facilities. Observational data identified that four AEDs were physically located alongside 


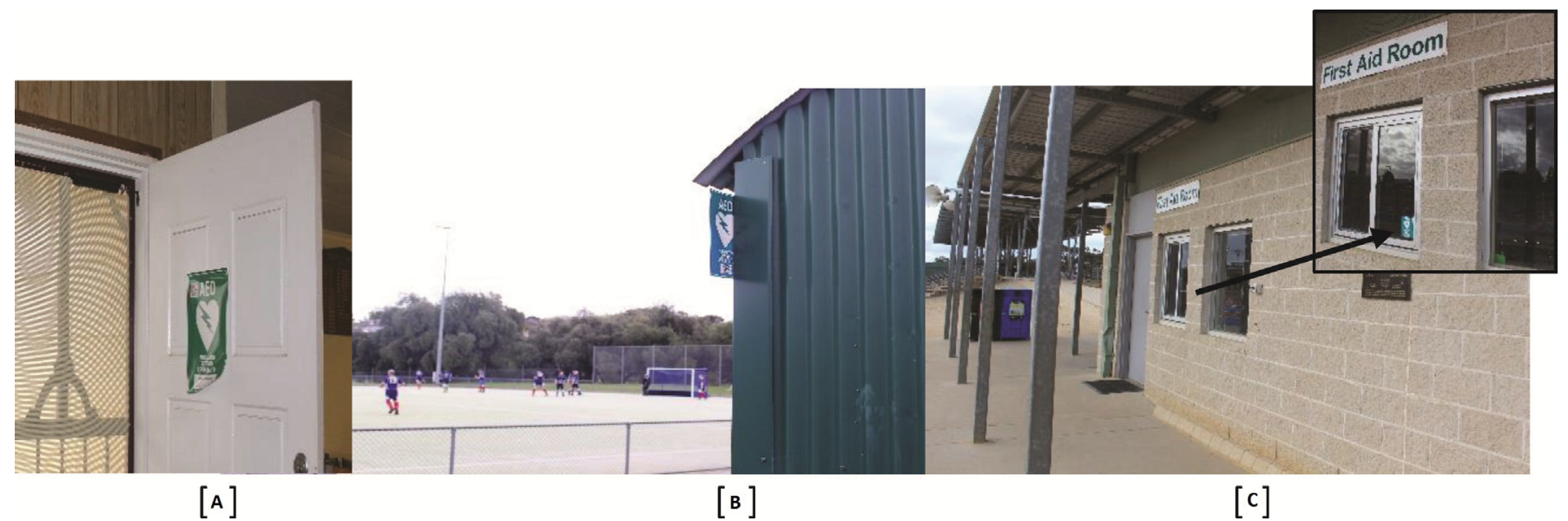

Figure 1 AED sticker sign examples where they were $(A)$ visibly worn/peeling from the surfaces; $(B)$ small and relatively obscure or (C) or unable to be seen from all areas of a sports field or precinct.

an action plan in the form of an information sheet or booklet. Other clubs stored emergency plans in a separate location to the AED. In total, seven clubs had developed their own action plan, five lacked emergency plans and for one, this was unknown (the 14 th club was undergoing renovation and unable to be accessed for the audit).

Well we were required to develop a medical emergency plan as part of our application and that's the first time we had one. So, I developed one which was basically about numbers to call in various emergencies and locations to provide instructions to the emergency vehicles, etc. (INTERVIEW C)

That is a simple template that I got from [the program], as part of the application process ...it's basically tailor-made for the process. You know being a key requirement. (INTERVIEW K)

As an underpinning concept of the DSCF programme, embedding new safety planning into a sport settings required actions additional to simply installing an AED or having an action plan. The programme dictated that all members and users of the facility should know about safety resources. The data collection documented how clubs/facilities shared emergency information pertaining to AED and planning document availability with members and the wider community. Many clubs used information and communication technology including dedicated apps, websites and social media.

Our team app, while everyone is on team app, they don't tend to read everything as well, but it's like a social media, but it belongs to us. (INTERVIEW B)

That would probably be on our club website and then when we start our season they'd be saying that this is our protocols, this is what we suggest that we do, so everyone is aware of that. Presuming they read their emails. (INTERVIEW G)

Oh Facebook. Social media initially, and we use email, but I'm finding in this day and age, social media, because of its reach, is much better than email and the website in effect. I think now, in these days, unless you're buying something online, I'm finding it's the social media, it's just reach alone, I can hit four or five hundred people in just one post. (INTERVIEW K)

As noted earlier, accessibility of the AED was restricted to club opening hours. Externally located identification of the AED location was limited. Even so, interviewees saw the logic of external signage.
No, we don't have any additional signage, which-if we were provided it and there was an external sign or something like that, that could be something to consider, as an organisation or from the Government's perspective. Because although it's not exactly a public space, it is a public place. So if there was sort of some public awareness that there was a defib here, I-that might be attractive. (INTERVIEW L)

Some interviewees were concerned by a lack of public knowledge about the AED location. But they did not know how to go about promoting this.

\section{Sustainability}

The third component investigated in interviews related to practical requirements for AED checking, occasional maintenance and how clubs/facilities ensured this process would occur including responsibility. Although not onerous, the AED has some technical maintenance requirements. Many clubs had integrated this maintenance within existing systems, while others intended to do so but had not yet managed to.

We do, so we included that in our maintenance schedule for our fire extinguishers, so we tied it in with that. So test and tagging for electrical equipment, fire extinguishers and now the defib are all on the same annual cycle and we get them tested around September every year, so we do the test. I'm pretty sure on that defib there was a way to test the battery and everything on there. (INTERVIEW N)

We certainly are planning to get a-try and set up a system to happen before the start of each main year. So, because we are mainly, our main focus is a winter sport, we would probably get it regularly done in say February or March leading into the next year. That's the plan. How well documented that is, I don't think it's necessarily there. (INTERVIEW D)

No, I know that they have a cycle obviously where the batteries and that have got to be replaced. So, look, to be honest, no. That's something we probably need to plan for and it's difficult in clubs with volunteers. But, look we've-I guess since I came on to the committee a couple of years ago, we've set up like our own Dropbox now, we centralise our file storage and our procedures and everyone in the committee has access and so forth. So ideally there's information there, we just need to work out a way to let people know-who are not part of that, that it's there. (INTERVIEW F)

For some clubs, by 6-12 months postdelivery, problems with maintaining AED location visibility through signage were apparent: 
No, all we've got up is those containers and the boxes. There may have been signage in the box but I didn't see any. At that stage, we did - we have renovated the whole lot recently, so the signage may have been there before and it's come down. But I can't remember the defibs. I know all the staff know where the defibs are. (INTERVIEW E)

The challenges of how club/facility members can continue to remain up to date with the knowledge and confidence to use the AED was also raised.

...it all gets back to that question I said before, is that unless there's regular training, unless you roll it out en masse, you know it's very hard to be confident that people would know how to use the unit. (INTERVIEW K)

\section{Active engagement}

Interview questions sought to identify how the DSCF programme fit into broader, long-term safety planning. For some clubs/facilities, this equipment formed part of an ongoing commitment to emergency management. Others considered the AED just a device to have with no further requirements and there was little evidence of any obvious change towards ongoing engagement with emergency planning.

Yes, it all came in the package-that was the sticker that [the delivery agent] put on. So yeah that's pretty much it. (INTERVIEW K)

'We talk about it, but...have we got enough written down? I don't know....we do-like I said, we do have first aid policies and things like that, but since the defib has come along, have we done enough to -we've certainly had the conversations. But we haven't got a formalised emergency plan per se. (INTERVIEW B)

Interviewees indicated awareness that the programme required participating clubs/facilities to develop or update an emergency plan, but were not clear on when or how it would be managed.

Well I suggested based on the application, again part of the application there were some key requirements. We're supposed to have a medical evacuation plan. (INTERVIEW K)

\section{DISCUSSION}

This study was designed to identify the extent to which AEDs and emergency action planning had been integrated into sport clubs'/facilities' practices approximately 12 months after an AED and training programme had been delivered. We found that there were some common difficulties for clubs/facilities in following through the programme's full implementation in terms of both the AED specifically and the planning for medical emergencies more broadly.

For the AED, we identified issues with location, security, visibility/signage and ongoing maintenance. While all clubs/facilities had some form of signage in the AED location's immediate area, most commonly stickers and for some, larger printed signs, it was inadequate for the environment and proved unsuitable for outdoor use, being worn or faded within 6-12 months. Simple suggestions were identified to increasing the awareness and visibility of the AED presence such as providing more effective signage, adapted for outdoor sport settings.

An AED is not '... a fixed, objective, or purely physical object' but rather part of 'a broader network of people, organisations, and other devices'. ${ }^{21}$ This network view was useful for identifying potential problems, particularly with AED upkeep (eg, checking battery life) in an environment where there is a high turnover of personnel, which is often the case in volunteer-driven community sport. Upkeep of the AED at many locations was reliant on the original provider of the AEDs to notify clubs/facilities annually about ongoing monitoring and management. This hands-off ownership has potential for failure, which could prove catastrophic if discovered when the AED is actually needed. Maintenance triggers were suggested by some participants to align with other safety measures, such as smoke detectors. In line with existing public messaging around daylight savings in parts of Australia, including Victoria, to 'change your clock, check your smoke alarm', some participants planned to use this timing as a reminder for their AED checks too.

In terms of emergency planning, some clubs/facilities were successfully prompted by the requirements of the DSCF programme, that is, participants were required to update their medical emergency documentation and, therefore, they did so. In contrast, changes had not yet been made at many facilities because of limited time and a lack of priority. Where and how medical emergency planning fits among other club priorities (child protection, coaching, uniforms and equipment, other injury management including heat and concussions) is an important consideration. ${ }^{22}$

Proactive risk management approaches are beneficial in protecting both sporting organisations and their members and there exists clear opportunity to adopt successful practices from occupational health settings. ${ }^{23}$ Safety in community sport clubs/ facilities can easily become reactive and unstructured partly owing to there being limited paid positions at the community club level. Government-led initiatives such as the DSCF programme, and support from peak sports bodies who provide policy and rulings, can only help so much in keeping participants both active and safe. This is because it is not interventions that work to promote sport safety, but rather it is people who make interventions work, on the assumption they adopt them. Integration of the AED and medical planning to fit the unique needs of each club are important, ideally in a way that avoids reliance on specific individuals. The importance of considering a full range of setting-level influences on the delivery of safety programmes and their long-term maintenance was demonstrated by a recent ecological evaluation of the implementation of a community sport safety programme. ${ }^{24}$ Essentially, an AED and training cannot be simply provided with an expectation that the emergency process is optimal when it is actually required.

\section{Limitations}

With little previous work considering AED implementation in sport settings, this study was designed as a descriptive case study, which presents inherent limitations, particularly in terms of generalisation to other settings or safety issues. For this analysis, themes were predefined and through the data collection phase, we sought meaning saturation to ensure that we had a full understanding of the issues within each theme. ${ }^{18}$ Fourteen interviews were conducted, which is considered acceptable for achieving meaning saturation although it remains possible that other clubs/ facilities from the 200 participants could have differing views. Although the interviews were of a relatively short duration, the research aim did not require more time as we were focused on eliciting practical aspects of programme implementation. The interviews covered the same general areas of information at each club/facility making use of short open-ended questions and prompt format, which facilitated timely responses that could be analysed and compared under a qualitative description analysis approach. The interviews were also undertaken within the sport clubs setting itself-often while sports activities were ongoing-and we were thus constrained to what was pragmatic, 
feasible and practical at the time for the interviewees. Only investigations that take into account actual use of the AED or the emergency process in action can provide a true measure of effectiveness of these programmes. However, cardiac events in sport are fortunately rare making this approach non-feasible. Further, evidence of even one life saved can be argued as being demonstrative of effect.

Research conducted in other public spaces such as shopping centres and airports, inspired parts of our research design..$^{10} 19$ While the specific results cannot be applied outside of Victorian community sport club settings, the key messages provide important safety insights and considerations that are applicable to a range of contexts and settings. The conduct of similar observational checks, and translation of key interview questions to a questionnaire format, could enable other institutions (eg, universities, workplaces) to evaluate emergency planning processes and knowledge, and to identify action points for improvement. Out of hospital survival for SCA is substantially improved with rapid bystander recognition and response and this type of research that optimises the chain of survival, ${ }^{25}$ with AEDs available in sport settings being only one small part of this.

\section{CONCLUSIONS}

This study identified several practical problems in the implementation of a safety programme in conjunction with the availability of an AED, including where to store the AED, how to make its presence known to the community and how it fits with other club/facility practices. Further consideration of what works to increase awareness and integration of AEDs and emergency planning in sport and other settings remains an important task in improving outcomes for cases of out of hospital cardiac arrest.

\section{Twitter Lauren V Fortington @|fortington}

Acknowledgements The authors thank all participants for their time and willingness to share their experiences in this study. Thanks also to Dr Damian Morgan for assistance with the larger project from which this paper derives. LVF and CFF are part of the Australian Centre for Research into Injury in Sport and its Prevention (ACRISP) at Edith Cowan University. ACRISP is one of the international research centres for the prevention of injury and protection of athlete health supported by the International Olympic Committee.

Contributors LVF and CFF designed the study and were awarded funding for the larger programme of work to which this study contributes. SB and LVF performed the data collection and analysed the data. LVF wrote the manuscript. CFF and SB provided input to interpretation of results and critical insights for the manuscript. All authors made a substantial contribution to the information and material submitted and have read and approved the final version.

Funding The authors acknowledge the support of the State Government of Victoria, which provided funding for conduct of the project from which this study is derived.

Competing interests None declared.

Patient and public involvement statement There was insufficient time available for public and patient involvement in the study design and reporting; however, there was indirect contribution to the research questions and survey design through two earlier studies conducted prior to this study.

Patient consent for publication Not required.

Ethics approval The project was conducted with approval from the Federation University Australia Human Research Ethics Committee (B17-098), where the authors were based at the time of data collection. Participants provided signed consent forms before the interview.

Provenance and peer review Not commissioned; externally peer reviewed.

Data availability statement No data are available. Data are not available for public release as it was not part of the original approval and consent.

Open access This is an open access article distributed in accordance with the Creative Commons Attribution Non Commercial (CC BY-NC 4.0) license, which permits others to distribute, remix, adapt, build upon this work non-commercially, and license their derivative works on different terms, provided the original work is properly cited, appropriate credit is given, any changes made indicated, and the use is non-commercial. See: http://creativecommons.org/licenses/by-nc/4.0/.

\section{ORCID iDs}

Lauren V Fortington http://orcid.org/0000-0003-2760-9249

Sheree Bekker http://orcid.org/0000-0003-0161-6280

Caroline F Finch http://orcid.org/0000-0003-1711-1930

\section{REFERENCES}

1 Maron BJ. Sudden death in young athletes. N Engl J Med 2003;349:1064-75.

2 DeJesus PW, Willoughby DeJesus P. Charging up the public for automated external defibrillators. Crit Care 2005;9:147.

3 Fortington LV, Bekker S, Morgan D, et al. "It doesn't make sense for us not to have one"-Understanding reasons why community sports organizations chose to participate in a funded automated external defibrillator program. Clin I Sport Med 2019;29:324-8.

4 Australasian College of Sport Exercise Physicians (ACSEP). Position statement on preparticipation cardiac evaluation in young athletes, 2018. Available: www.acsep.org. au/page/resources/position-statements/position-statements [Accessed 08 Aug 2019].

5 Finch CF, Donaldson A. A sports setting matrix for understanding the implementation context for community sport. Br J Sports Med 2010;44:973-8.

6 Saunders N, Otago L, Romiti M, et al. Coaches' perspectives on implementing an evidence-informed injury prevention programme in junior community netball. $\mathrm{Br}\rfloor$ Sports Med 2010;44:1128-32.

7 Fortington LV, Donaldson A, Lathlean T, et al. When 'just doing it' is not enough: assessing the fidelity of player performance of an injury prevention exercise program. J Sci Med Sport 2015;18:272-7.

8 Fortington LV, West L, Morgan D, et al. Implementing automated external defibrillators into community sports clubs/facilities: a cross-sectional survey of community club member preparedness for medical emergencies. BMJ Open Sport Exerc Med 2019;5: 000536.

9 Haskell SE, Post M, Cram P, et al. Community public access sites: compliance with American heart association recommendations. Resuscitation 2009;80:854-8.

10 Huig IC, Boonstra L, Gerritsen PC, et al. The availability, condition and employability of automated external defibrillators in large city centres in the Netherlands. Resuscitation 2014;85:1324-9.

11 Smith CM, Colquhoun MC, Samuels M, et al. New signs to encourage the use of automated external defibrillators by the lay public. Resuscitation 2017;114:100-5.

12 Aagaard R, Grove EL, Mikkelsen R, et al. Limited public ability to recognise and understand the universal sign for automated external defibrillators. Heart 2016;102:770-4.

13 Creswell JW. Research design : qualitative, quantitative, and mixed methods approaches. Los Angeles: SAGE, 2009

14 Glasgow RE, Vogt TM, Boles SM. Evaluating the public health impact of health promotion interventions: the RE-AIM framework. Am J Public Health 1999;89:1322-7.

15 Glasgow RE, Vogt TM, Boles SM. RE-AIM website, 2019. Available: www.re-aim.org/ [Accessed 02 Aug 2019].

16 O'Brien J, Finch CF. The implementation of musculoskeletal injury-prevention exercise programmes in team ball sports: a systematic review employing the RE-AIM framework. Sports Med 2014;44:1305-18.

17 Kessler RS, Purcell EP, Glasgow RE, et al. What does it mean to "employ" the RE-AIM model? Eval Health Prof 2013;36:44-66.

18 Hennink MM, Kaiser BN, Marconi VC. Code saturation versus meaning saturation. Qual Health Res 2017;27:591-608.

19 Yoon CG, Jeong J, Kwon IH, et al. Availability and use of public access defibrillators in Busan metropolitan City, South Korea. Springerplus 2016;5:1-5.

20 Sandelowski M. Whatever happened to qualitative description? Res Nurs Health 2000;23:334-40

21 Timmons S, Crosbie B. Why do organisations implement automated external defibrillators? Health Risk Soc 2014;16:355-69.

22 Bekker S, Finch CF. Too much information? A document analysis of sport safety resources from key organisations. BMJ Open 2016;6:e010877.

23 Donaldson A, Forero R, Finch C. The first aid policies and practices of community sports clubs in northern Sydney, Australia. Health Promot J Aust 2004;15:155-61.

24 Donaldson A, Gabbe BJ, Lloyd DG, et al. Controlled ecological evaluation of an implemented exercise training programme to prevent lower limb injuries in sport: differences in implementation activity. Inj Prev 2019;25:480-6.

25 de Visser M, Bosch J, Bootsma M, et al. An observational study on survival rates of patients with out-of-hospital cardiac arrest in the Netherlands after improving the 'chain of survival'. BMJ Open 2019:9:e029254. 